\title{
AFETIVIDADE E APRENDIZAGEM - PERCEPÇÕES DO PROFESSOR NO ENSINO FUNDAMENTAL I
}

\author{
AFFECTIVITY AND LEARNING- TEACHER'S PERCEPTIONS IN \\ ELEMENTARY SCHOOL I
}

Maria Luiza Sobreira de Oliveira ${ }^{1}$

RESUMO: A presente pesquisa é resultado da reflexão sobre como os professores alfabetizadores percebem a afetividade na sua prática, a importância e relação que estabelecem entre afetividade e aprendizagem. O público-alvo foi um grupo de 15 professores de três escolas de um município da Grande São Paulo. Considera-se a partir das análises que os professores percebem a afetividade como essencial, no processo de alfabetização, tanto que, pontuaram que deveria ser considerada a partir da escolha da classe. O professor acredita que a afetividade se relaciona com a cognição e que essa relação se dá por meio do vínculo nas relações: professoraluno; aluno-aluno, aluno-conhecimento, e pela motivação. A importância apontada para a afetividade na prática, mais uma vez se relaciona à motivação que impulsiona o aluno durante o processo de aprendizagem. Os relatos nas entrevistas, demonstram nas diversas situações que, quando se há respeito, compreensão, diálogo e principalmente quando os aspectos afetivos e cognitivos do sujeito são considerados no processo de aprendizagem, a alfabetização acontece de forma satisfatória, no entanto, nos chama atenção alguns professores apontarem para a afetividade como importante para manter a sala de aula disciplinada, esse dado nos leva a refletir que em muitas situações o professor pode utilizar a afetividade como meio de controle de seus alunos e não como favorecedora da aprendizagem.

Palavras-chave: Alfabetizadores. Afetividade. Aluno. Aprendizagem. Percepção.

ABSTRACT: The present research results from the reflection on how the literacy teachers perceive the affectivity in their practice, the importance and relation that establish between affectivity and learning. The target audience was a group of is teachers from three schools in a municipality of Greater São Paulo. It is considered from the analysis that teachers perceive affectivity as essential, in the process of literacy, so much that, they pointed out that it should be considered from the choice of class. The teacher believes that affectivity is related to cognition and that this relationship occurs through the bond in relationships: teacher-student; student-student, student-knowledge, and motivation. The importance pointed to affectivity in practice once again relates to the motivation that drives the student during the learning process. The reports in the interviews show in the various situations that, when there is

\footnotetext{
${ }^{1}$ Graduada em Pedagogia pelo Instituto de Ensino Superior de Cotia, Especialização em Psicopedagogia pela Faculdade Anhanguera, Mestra em Psicologia Educacional pelo Centro Universitário FIEO UNIFIEO, 2018. Atuou como professora de Educação Básica no Município de Itapevi - SP e como tutora EAD na Universidade Paulista- Unip. Atualmente trabalha na Secretaria de Educação do município de Itapevi no setor que representa a Educação Especial - Gerência de Atendimento Educacional Especializado e atua como Web Tutora na FAEL - Faculdade Educacional da Lapa - Curitiba -PR. Autora da resenha do livro: A mediação das emoções em professores alfabetizadores. Appris. São Paulo: 2015. 208 p. da autora Cleomar Azevedo pela Educar em Revista publicação em 2017. E- mail: malusobreira@gmail.com.
} 
respect, understanding, dialogue and especially when the affective and cognitive aspects of the subject are considered in the learning process, literacy happens satisfactorily; teachers point to affectivity as important to keep the classroom disciplined, this data leads us to reflect that in many situations the teacher can use affectivity as a means of control of their students and not as a conducive to learning.

Keywords: Literacy teachers. Affectivity. Student. Learning. Perception.

\title{
INTRODUÇÃO
}

É consenso para muitos estudiosos do processo de aprendizagem que a afetividade e o controle das emoções por parte do professor alfabetizador é um fator de primordial importância neste contexto.

Conceitos importantes de teóricos da aprendizagem como Wallon, Vygotsky e Piaget serviram de base para uma pesquisa implementada em três escolas de um município da Grande São Paulo, onde 15 docentes foram entrevistadas com o intuito de investigar o quanto são capazes de perceber a afetividade em suas rotinas em salas de aula. Para efeito de recorte, apenas as 8 primeiras entrevistas foram publicadas neste artigo. $O$ resultado completo da pesquisa será publicado em próximo trabalho a ser publicado.

Entre estes conceitos, Azevedo (2015) considera a afetividade e mediação das emoções dos professores alfabetizadores como fatores principais para a alfabetização. Ela coloca que esta mediação das emoções por parte das professoras alfabetizadores é algo primordial para a construção da aprendizagem, pois está relacionada a interações sociais que não se limitam apenas ao aspecto intelectual, mas também afetivos, de forma que:

\begin{abstract}
A prática do professor alfabetizador deve estar voltada à determinação de instâncias que interferem na aprendizagem. Várias instâncias que interagem na construção do conhecimento e nessas deve estar presente a interação entre a estrutura lógica a estrutura simbólica, o corpo e o organismo em um determinado contexto social (AZEVEDO, 2015, p. 21).
\end{abstract}

Logicamente, podem-se considerar como instâncias fundamentais a afetividade e o gerenciamento das emoções pelos docentes, de forma que tal controle permita guiar os alunos à construção do conhecimento.

\section{Aprendizado e afetividade}

O material teórico que fornece a base para a pesquisa consiste nos conceitos de Wallon, Vygotsky e Piaget acerca de temas como a afetividade na interação professor-aluno em ambiente escolar enquanto alicerce para a construção da aprendizagem. 
Sob a perspectiva de Wallon (1968), a afetividade se manifesta de diversas formas no processo de aprendizagem. A princípio, ela se dá de forma mais orgânica, mas à medida que a criança vai crescendo, sofre uma progressão e vai se relacionando cada vez mais com o social, de forma que é possível considerar como processos afetivos todos os estados de sensações como prazer ou desprazer, sejam estas experiências agradáveis ou não. Relaciona-se à condição de afetação. É ser afetado por sensações. Já as emoções, são atitudes que estão associadas a determinadas situações. Nesta perspectiva a emoção exterioriza a afetividade.

Vygotsky (2003) demonstra a relação entre emoção e cognição sob outra perspectiva que não a dos aspectos biológicos: a perspectiva do desenvolvimento social. A vida cognitiva e emocional de uma criança é construída socialmente, na interação com o outro e mediada pela linguagem pela qual o indivíduo se apropria dos conhecimentos socialmente valorizados pelo grupo social em que está inserido, ou seja, o desenvolvimento humano ocorre em ambientes organizados culturalmente e socialmente regulados através de interações sociais.

Desta forma, o pensador considera a compreensão da leitura e escrita pela criança como algo construído nas relações sociais, na relação com o outro e com o conhecimento. É a troca de experiências que possibilita a aquisição da escrita e o acesso ao mundo simbólico. Assim, destaca a importância do papel do professor como mediador no processo educativo.

[...] o professor desempenha um papel ativo no processo da educação: modelar, cortar, dividir e entalhar elementos do meio para que estes realizem o objeto buscado. O processo educativo, portanto, é trilateralmente ativo: o aluno, o professor e o meio existente entre eles são ativos (VYGOTSKY, 2003, p. 79).

Piaget (198I) considera que o aspecto da afetividade é paralelo ao desenvolvimento cognitivo. $O$ afeto, nesta perspectiva, inclui sentimentos, interesses, desejos, tendências, valores e emoções, apresentando muitas dimensões. São sentimentos subjetivos, como raiva ou tristeza, e expressivos, como sorrisos ou gritos. $O$ afeto, quando se refere ao desenvolvimento intelectual, se relaciona ao interesse, pois para ativar a estrutura do conhecimento do sujeito, é preciso que seja acionado algo que dê origem ao esforço e assim, fazer a estrutura do conhecimento funcionar. Dessa forma, o interesse é considerado o acionador que leva o sujeito a desenvolver-se intelectualmente.

É o interesse que influencia a seleção das atividades intelectuais, ou seja, nos esforçamos para aprender aquilo que nos interessa. É desta forma que os esquemas cognitivos se desenvolvem. Para Piaget, os aspectos cognitivos e afetivos fazem parte do funcionamento 
intelectual, ou seja, o comportamento é constituído pelos elementos afetivos e cognitivos. Assim, considera que:

É impossível encontrar um componente oriundo apenas da afetividade, sem nenhum elemento cognitivo. É, igualmente, impossível encontrar um comportamento composto só de elementos cognitivos [...] embora os fatores afetivos e cognitivos sejam indissociáveis num dado comportamento, eles parecem ser diferentes quanto à natureza [...] é óbvio que os fatores afetivos estão envolvidos, mesmo nas formas mais abstratas de inteligência. Para um estudante resolver um problema de álgebra ou para um matemático descobrir um teorema, deve haver um interesse intrínseco, um interesse extrínseco ou uma necessidade de partida. Enquanto trabalha, estados de prazer, desapontamento, ansiedade tanto quanto sentimentos de fadiga, esforço, aborrecimento, etc., entram em cena. Ao finalizar o trabalho, sentimentos de sucesso, ou fracasso podem ocorrer; e, finalmente o estudante pode experimentar sentimentos estéticos fluindo da coerência de sua solução (PIAGET, 200I).

Além destes três teóricos citados acima, buscou-se algum apoio na teoria dos afetos, do filósofo holandês Baruch Espinoza, citado por Gleizer (2005). Aqui, os afetos são apresentados em estreita relação com o conhecimento. Para Espinoza, tratam-se de afecções (as afetações que sofremos) pelas quais a potência de agir poderia ser aumentada ou diminuída.

Estas afecções, na concepção do filósofo, são as afetações que o corpo sofre. Durante uma interação acabam ocorrendo alterações e a potência do agir aumenta ou diminui dependendo do afeto. Gleizer apresenta a seguinte definição de afeto por Espinoza:

\footnotetext{
Um afeto é uma afecção que faz variar positiva ou negativamente a potência de agir. Desta forma, uma afecção neutra, isto é, que deixa invariável a potência de agir, não tem dimensão afetiva. Assim, se todo afeto é uma afecção, nem toda afecção é um afeto. A variação positiva da potência de agir - ou seja, sua passagem a uma maior perfeição ou força de existir constitui a alegria, enquanto sua variação negativa - isto é, sua passagem a uma menor perfeição ou força de existir - constitui a tristeza (GLEIZER, 2005, p. 35).
}

Contextualizando a ideia de afetividade na aprendizagem, no cenário brasileiro, é inegável a contribuição da construtivista Emília Ferreiro, que foi discípula de Piaget, cujos estudos, foram apresentados no Brasil em causando grande impacto. A Psicolinguista busca explicar como ocorre a aprendizagem da leitura e escrita nas crianças. Não é uma metodologia, mas sim, interpretação dos processos de aprendizagem, sob a perspectiva do sujeito que aprende e não de quem ensina. 
Sobre Ferreiro, Azevedo (2012) enfatiza a importância de não desvincular suas pesquisas das de Piaget, pois as propostas representam o pensamento epistemológico da escola de Genebra, e acrescenta:

A grande contribuição de Emília Ferreiro é provocar nos educadores uma mudança nos conceitos que, durante anos, estiveram presentes no seu pensamento e nortearam a prática educativa que tem resultado em dificuldades na aprendizagem da leitura e da escrita, especialmente quando se trata das séries iniciais e no chamado processo de alfabetização (AZEVEDO, 2012, p. 46).

Para Ferreiro (1987), a aprendizagem no sistema tradicional era considerada de natureza gráfica. Porém, o processo de alfabetização não é mecânico, o que torna inútil todo esse treinamento ao qual a criança é submetida na proposta tradicional. Desta forma:

Se o enfoque da aprendizagem é conceitual, envolvendo processos cognitivos como atenção, compreensão, observação, elaboração, seleção, ordenação, sequenciação, isso significa que a alfabetização trata-se de uma construção mental e na interação com ação sobre os objetos, a criança vai modificando gradualmente suas estruturas cognitivas, a partir daquelas que estão disponíveis. Sem ação interacional, não há como a criança adquirir e desenvolver os processos cognitivos envolvidos na aprendizagem da leitura e a escrita (FERREIRO, 1987, p. 98).

Para Ferreiro, sem interação, a criança não desenvolve os processos cognitivos que estão envolvidos na aprendizagem da leitura e escrita. Nesta perspectiva, a criança é considerada como detentora de um grande potencial, carregando consigo uma bagagem que favorece a aprendizagem. Dessa forma, tudo que a criança faz deve ser valorizado, e o papel do professor é construir, por meio dessa afetividade, esquemas de ação alfabetizadora a partir do vocabulário da criança, seus interesses, gostos e brincadeiras.

\section{Metodologia da pesquisa}

O presente estudo foi realizado mediante uma abordagem qualitativa de cunho exploratório-descritivo. As escolas estudadas ficam em uma cidade da Grande São Paulo com cerca de 215 mil habitantes. A Secretaria da Educação desta cidade administra 68 escolas que atendem o Ensino Infantil, Fundamental I e Educação de Jovens e Adultos no Ciclo I.

Tais escolas atendem um número entre 300 e 800 alunos, nos períodos, matutino, vespertino. A estrutura física é comum a todas: salas de aula, sala de direção, coordenação e refeitório. São servidas duas refeições diárias. Em seus quadros de funcionários, contam com uma equipe técnico-administrativa que desempenha funções administrativas na secretaria da 
escola; auxiliares de limpeza de empresas terceirizadas; merendeiras de empresas terceirizadas; professores polivalentes e especialistas (nas áreas de Educação Física, inglês e Arte).

As professoras de Educação Básica I, chamadas polivalentes, apresentam formação em Pedagogia (licenciatura plena ou outra licenciatura com complementação pedagógica, conforme plano de carreira). São profissionais cujas idades oscilam entre 20 e 50 anos, sendo que a maioria delas está na faixa dos 40/50, com renda entre 3 e io salários-mínimos.

Os alunos das escolas pesquisadas são, em sua maioria, oriundos de famílias carentes. É normal que as mães trabalhem fora e não é raro que não haja uma presença paterna, o que ocasiona um deficit de atenção com os filhos e de participação dos pais na escola.

Três escolas fizeram parte da pesquisa e, originalmente, 30 professoras participariam. Porém, metade delas desistiu, causando a diminuição do número de professoras participantes para 15. Neste artigo, serão retratadas as entrevistas de 8 dessas profissionais. Em material futuro a pesquisa será abordada em sua totalidade.

A primeira etapa da pesquisa consistiu em visitas às instituições, para autorização dos gestores. No momento seguinte, houve novas visitas, desta vez no intuito de um primeiro contato com os professores e a entrega do Termo de Consentimento Livre e Esclarecido. Neste primeiro contato, os professores ficaram conhecendo a natureza da pesquisa e foram feitos os pedidos para que participassem.

As entrevistas foram agendadas individualmente, em horários que não afetassem as rotinas de trabalho. Os professores preencheram o questionário sociodemográfico em um dia e passaram por entrevista com áudio gravado em outro, possibilitando mais fluidez nos diálogos.

O questionário foi usado com a intenção de conhecer mais dos participantes, e nele estavam contidas questões envolvendo aspectos pessoais, econômicos e profissionais de cada participante, enquanto a entrevista tinha como objetivo captar as percepções dos professores a respeito de suas práticas.

As entrevistas estruturadas contaram com questões abertas, e ocorreram no horário pré-combinado com cada participante e nos locais de trabalho de cada um deles.

\section{Apresentação e discussão dos dados}

\section{Perfil sociodemográfico dos professores}

As figuras que seguem são os que apresentaram maior relevância para traçar o perfil do professor da rede municipal pesquisada. 
Os gráficos que seguem, são os que apresentaram maior relevância para traçar o perfil do professor da rede municipal pesquisada. Vale ressaltar que segundo os indicadores do INEP Censo 2017, no que se refere aos professores do Ensino Fundamental I, séries iniciais, a principal rede de ensino que estão vinculados é a rede municipal.

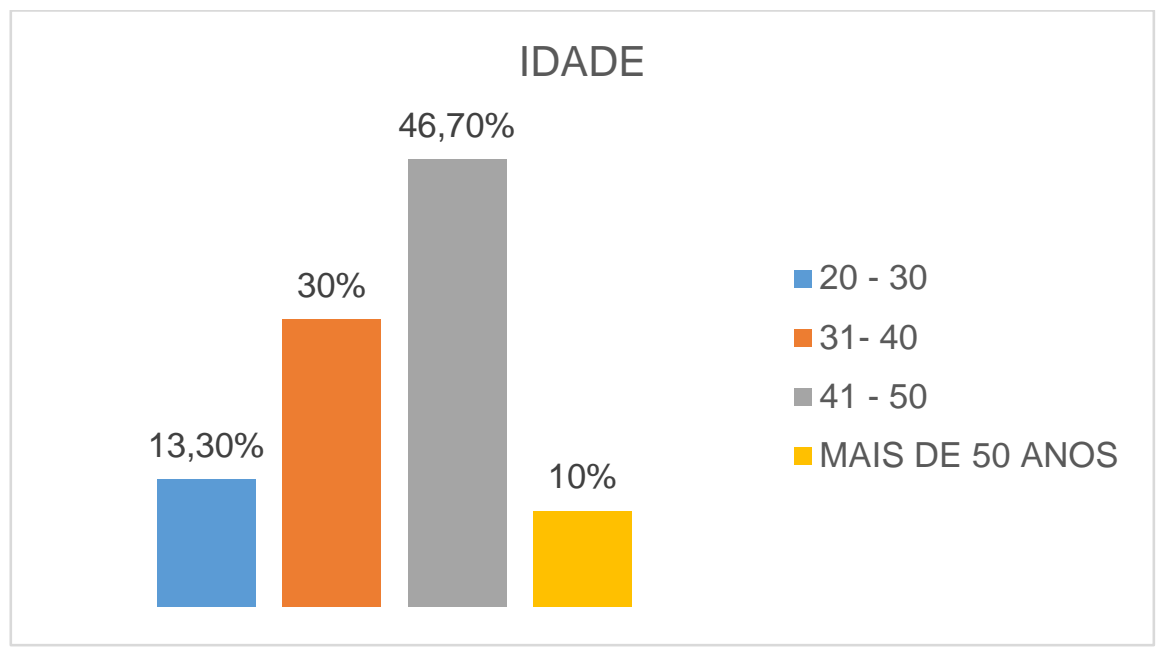

Gráfico I

De acordo com o gráfico idade (gráfico I), a faixa etária docente com maior percentual é 4I a 50 anos encontra-se com 46,7\%, seguido do percentual de 30\% para os participantes com

idades entre $3 \mathrm{r}$ e 40 anos. Os dados obtidos se relacionam com os do censo educacional INEP (2017), que indicam uma concentração de docentes nas faixas etárias de 30 a 39 anos e de 40 a 49, na educação básica em SP. Outro indicador que encontramos semelhança entre os dados coletados e o senso do INEP (2017) é o de formação inicial e acadêmica, apresentado abaixo:

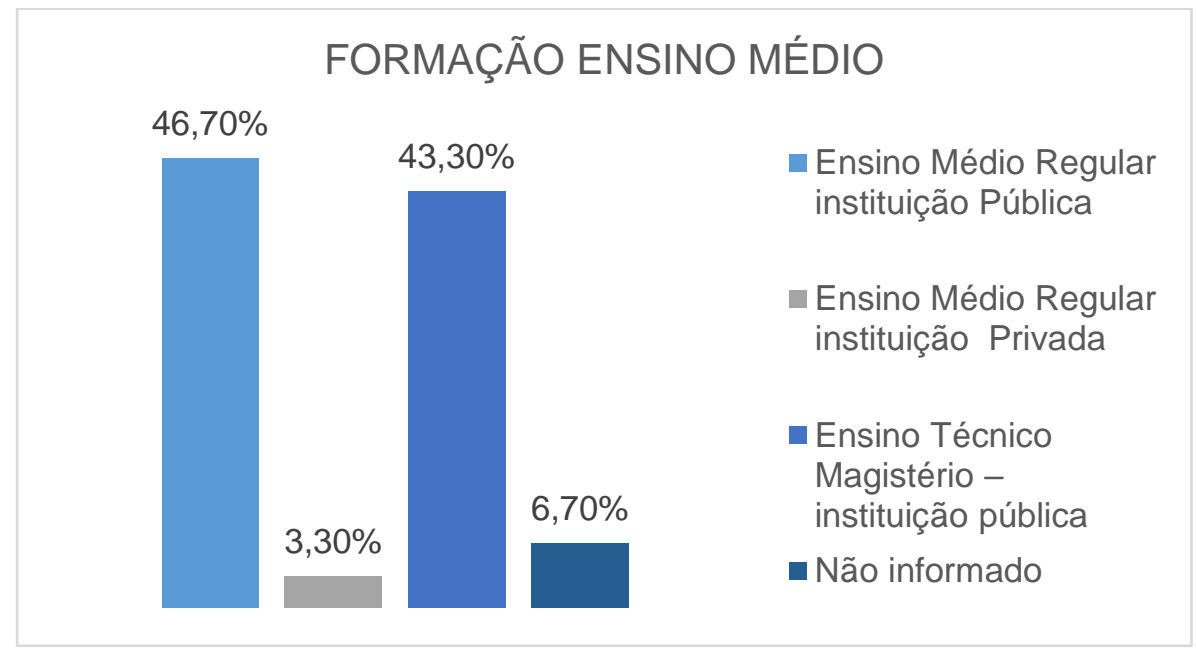

Gráfico 2 


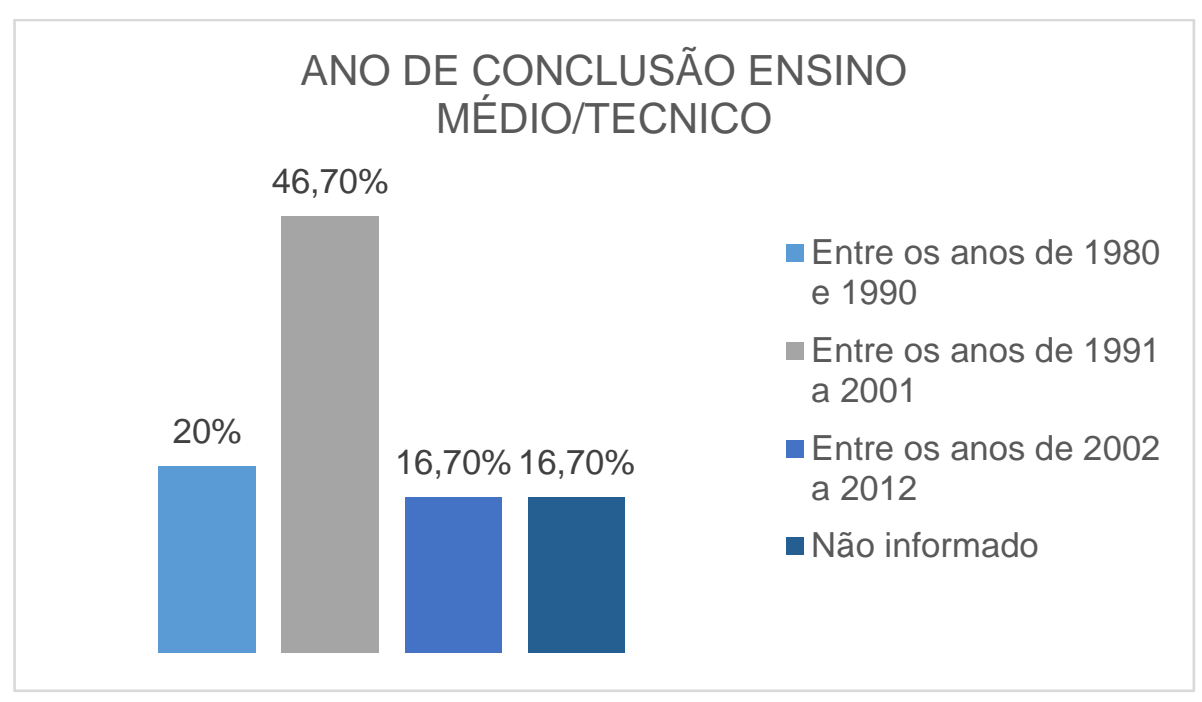

Gráfico 3

Nestes indicadores, merece destaque que quase o total dos professores pesquisados, fizeram toda a educação básica em instituição pública e o superior em instituição privada e ainda 100\% presencial, (gráficos 2,3) o que de certa forma demonstra o quadro atual da educação em que a maioria da população, docentes ou não, cursam o Ensino Básico público, mas ao buscar o curso superior, não consegue concorrer ao ensino público e dessa forma, acaba ingressando no privado, enquanto, a minoria que estuda na rede privada durante toda a educação básica, consegue concorrer ao ensino superior da rede pública. Esses dados constam no Instituto Brasileiro de Geografia e Estatística (IBGE), que apresenta a estatística de que um total de $73,5 \%$ de estudantes que frequentavam a escola pública, cursam graduação na rede privada.

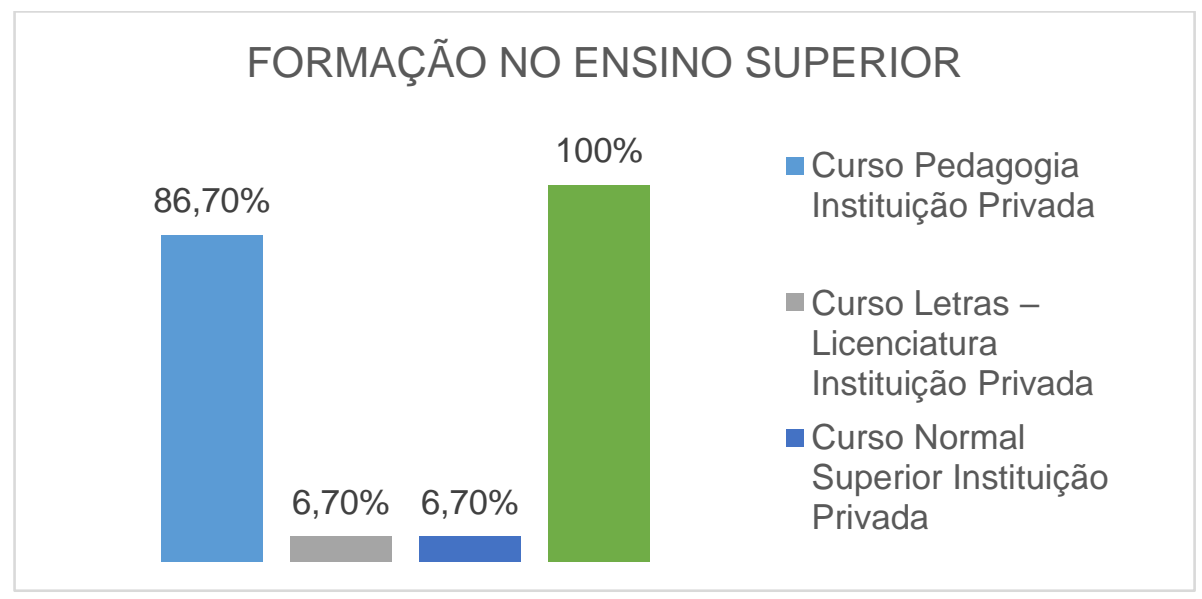

Gráfico 4 
No gráfico 4 podemos verificar que com relação à formação acadêmica o percentual obtido de 86,7\% na licenciatura em Pedagogia e 6,7\% Letras Licenciatura, assemelha-se com o percentual apresentado pelo INEP $2017 \mathrm{com} 76,2 \%$ dos professores apresentam curso superior completo com licenciatura. Acadêmica, percentual obtido de $86,7 \%$ na licenciatura em Pedagogia e 6,7\% Letras Licenciatura, assemelha-se com o percentual apresentado pelo INEP 2017 com $76,2 \%$ dos professores apresentam curso superior completo com licenciatura.

\section{PARTICIPOU DE CURSO DE ATUALIZAÇÃO}

\section{$76,70 \%$}

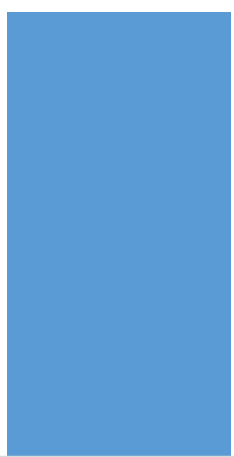

- Sim

- Não

$23,30 \%$

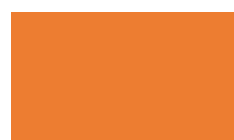

Gráfico 5

\section{QUAIS CURSOS}

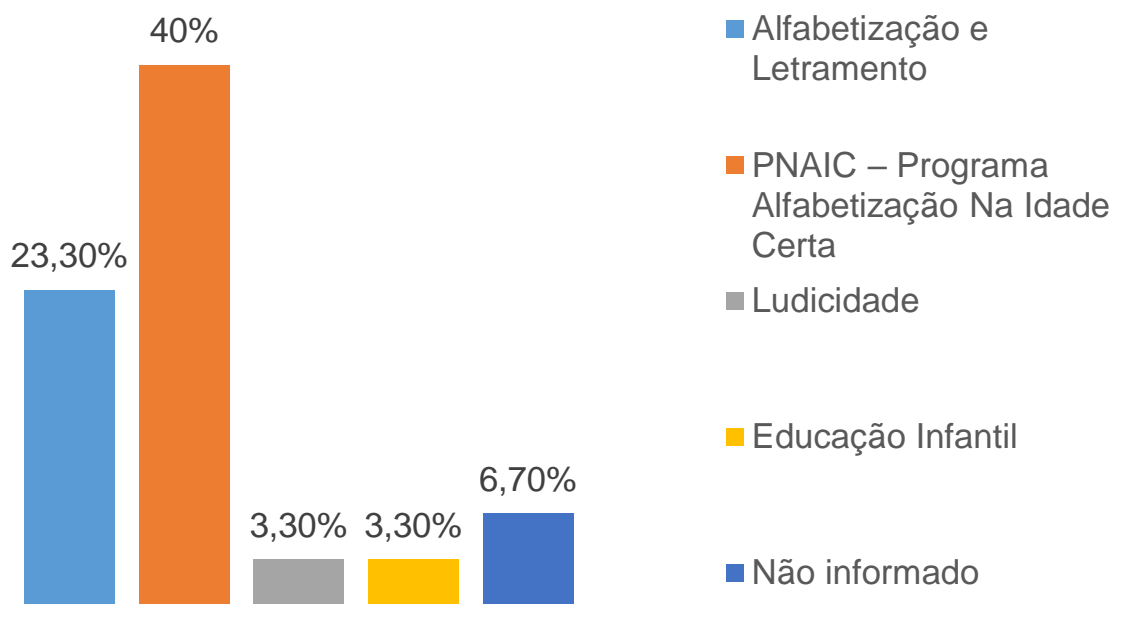

Gráfico o6 
Os gráficos o5 e 06 indicam que os professores alfabetizadores demonstram interesse em aperfeiçoar-se para oferecer um melhor ensino aos seus alunos, realizando cursos relacionados à alfabetização como: Programa Nacional da Alfabetização na Idade Certa, o PNAIC e a Alfabetização e Letramento. No entanto, demonstram participação apenas nos cursos oferecidos pela rede em que atuam.

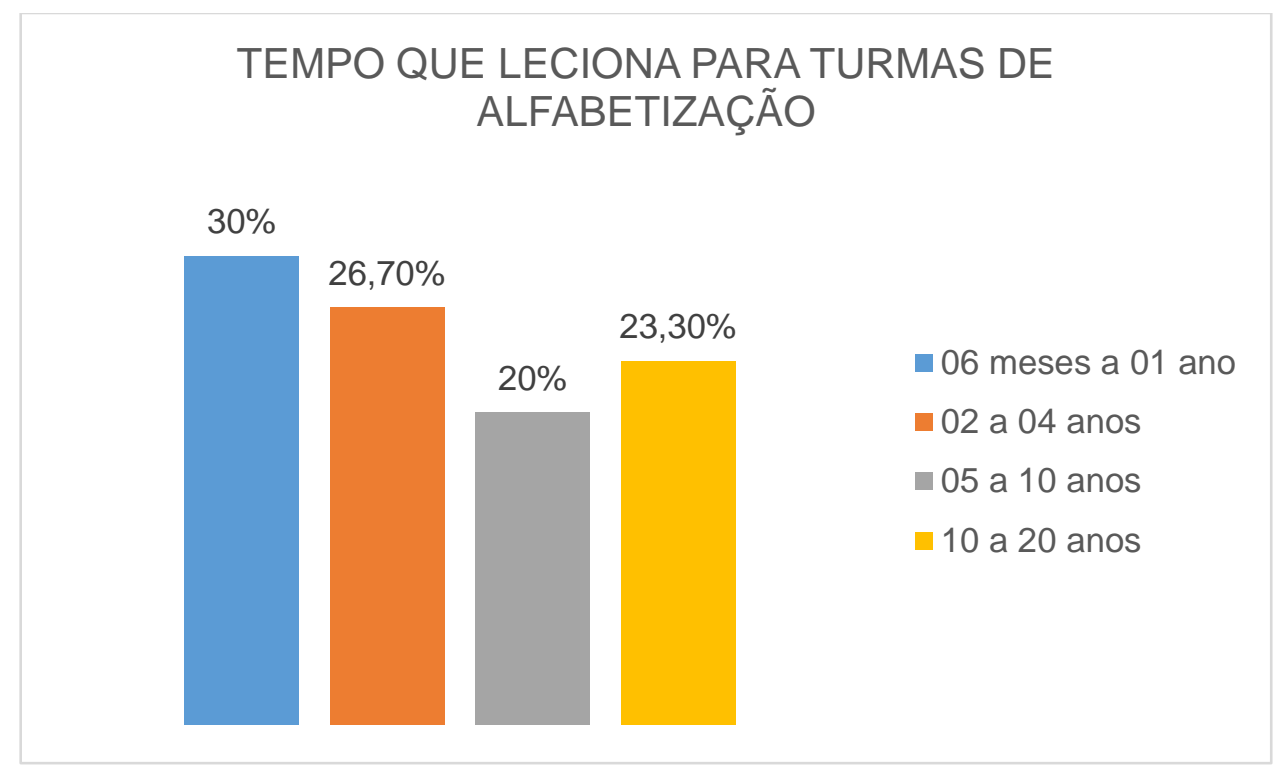

Gráfico 7

Os dados do gráfico o7 demonstram que a maioria dos participantes (30\%) corresponde a professores que trabalham com alfabetização de 06 meses a or ano, seguido por $26 \%$ de professores que trabalham com alfabetização de os a io anos. A maioria dos professores desta pesquisa lecionam a pouco tempo para turmas de alfabetização enquanto os mais experientes estão em outras turmas.

\section{Resultados das entrevistas semiestruturadas}

Os dados referentes às entrevistas semiestruturadas foram submetidos à análise de conteúdo, de forma que o pesquisador pode fazer inferências sobre qualquer um dos dados coletados. Para esta análise, foram utilizadas as informações contidas no questionário sociodemográfico e nas respostas às entrevistas sobre a prática na alfabetização, percepções sobre afetividade e cognição nesta etapa de aprendizagem. 
Os dados foram submetidos à análise de conteúdo, que segundo Franco (2012) trata-se de um procedimento de pesquisa que se situa em um delineamento mais amplo da teoria da comunicação e apresenta como ponto de partida a mensagem. Por meio da análise de conteúdo o pesquisador pode fazer inferências sobre qualquer um dos elementos da comunicação. Para Bardin:

\begin{abstract}
A análise de conteúdo pode ser considerada como um conjunto de técnicas de análises de comunicações, que utiliza procedimentos sistemáticos e objetivos de descrição do conteúdo das mensagens... A intenção da análise de conteúdo é a inferência de conhecimentos relativos às condições de produções e de recepção as mensagens, inferência esta que recorre a indicadores (quantitativos, ou não) (BARDIN, 1977, p. 38).
\end{abstract}

Nesta perspectiva,

Toda mensagem falada, escrita ou sensorial, contem potencialmente, uma grande quantidade de informações sobre seu autor: suas filiações teóricas, concepções de mundo, interesses de classe, traços psicológicos, representações sociais, motivações, expectativas, etc. (FRANCO, 20I2, p. 27).

O autor seleciona o que considera, mais importante das situações da vida humana e interpreta de acordo com seu quadro de referência. É relevante lembrar que essa seleção é preconcebida, uma vez que o autor, é um produto social, condicionado pelos interesses relacionados à sua época ou à classe que pertence.

Para a análise dos dados desta pesquisa foram utilizadas informações coletadas por meio do questionário sociodemográfico e entrevista sobre a prática na alfabetização; percepções sobre afetividade e cognição nesta etapa de aprendizagem. No total de is entrevistados com recurso de áudio, cujos objetivos foram: investigar a percepção do professor alfabetizador sobre afetividade na sua prática; analisar a relação que o alfabetizador estabelece entre afetividade-cognição e verificar a importância que o professor alfabetizador atribui à afetividade na sua prática.

Estes instrumentos foram aplicados em 30 participantes, no entanto, para a entrevista contamos apenas com 15. Os outros 15 desistiram durante o processo. A seleção dos participantes obedeceu a dois critérios: o professor deveria estar lecionando para turmas de 1. ou 2. ${ }^{\circ}$ anos e ser professor titular da sala, pois há casos do docente que leciona para determinada turma, fazê-lo em caráter provisório, por motivo de licença, ou outros.

Foram realizadas visitas em várias escolas municipais, no entanto, por motivo de aceitação dos professores em participar, realizamos as entrevistas em três instituições. Nestas 
a receptividade foi satisfatória, inclusive, a temática foi bem aceita pelos participantes, os quais solicitaram palestras para conhecer mais sobre o assunto.

O início da análise se deu por meio da leitura flutuante, que para Bardin (2010) compõe a etapa de pré-análise. Essa etapa foi realizada a partir das respostas transcritas dos participantes, para seguir com o conhecimento do nosso corpus. Os termos foram escolhidos por similitude, que tivessem relação com o que era buscado como resposta do objeto.

A entrevista foi composta por oito questões que visou coletar dados que pudessem responder ao objeto de pesquisa. Foram elencadas para este trabalho apenas as questões que foram consideradas pertinentes para o objetivo da pesquisa. Dessa forma, trouxemos as questões or: "O que o levou a querer lecionar para o r.ㅇ ou 2...$^{\circ}$ ano do ensino fundamental I"?; questão o6: "O que é afetividade para você? Conhece alguma concepção teórica que contemple afetividade? Comente"; questão 7: "Você estabelece relação entre afetividade e cognição? Explique" e questão 8: "A afetividade pode auxiliar na aprendizagem do aluno? Em quais situações de sua prática pedagógica você pôde perceber isso"? As demais questões serão utilizadas para estudos posteriores como artigos científicos.

É importante ressaltar que as entrevistas apresentadas são as que tiveram maior relevância com os objetivos propostos, contudo, todas as entrevistas com respostas dos is participantes.

A partir das entrevistas, foram criados itens de acordo com cada questão. Os indicadores surgiram a partir das palavras que mais sobressaíram nas respostas ou a partir do que os participantes apresentaram, ou seja, do que quiseram expressar.

Assim, os itens criados foram: "Entre o gosto e a obrigatoriedade na escolha da turma"; "Percepções, docente sobre afetividade"; "Afetividade e cognição: as relações que se estabelecem"; "Afetividade: contribuições para a aprendizagem". Cada questão resultou de or a 03 categorias, que demonstraram a percepção do professor.

\section{Entre o gosto e a obrigatoriedade na escolha da turma}

Este item resultou da questão: "O que o levou a querer lecionar para o I.. ou 2.ㅇ ano do ensino fundamental I"? I/3 dos docentes, deixaram claro que não tiveram escolha, passaram por um processo de atribuição, que considera fatores como tempo que atua na rede como docente e sua formação ao nível de especialização ou stricto sensu.

"De primeiro momento não foi escolha minha. [...] Tive que ficar com o que sobrou". (p.8, 2017). 
"Nós respeitamos uma ordem de classificação que a prefeitura coloca. [...] eu não tenho muito tempo de rede então eu fico com o que sobra". ( $\left.\mathrm{P}_{11,2017}\right)$.

Os discursos apresentados demonstram que esses participantes não puderam escolher suas salas considerando seus gostos ou afinidades, mas sim, por um processo que denominaram atribuição, que segundo os relatos se refere ao tempo que o professor apresenta na rede de ensino. Segundo os mesmos, a cada ano letivo, o docente agrega pontos que lhe garantem uma ordem no processo de atribuição de aulas. Embora o Plano municipal de educação do município pesquisado apresente como um dos principais objetivos, a manutenção de programas de formação continuada para professores do ensino fundamental, podemos inferir que oferecer a oportunidade de escolha de turmas aos docentes por suas afinidades $e$ classificação vem de encontro a dimensão afetiva que influencia o processo de ensinoaprendizagem, especialmente em turmas de alfabetização.

Para Tassoni (2013):

Toda aprendizagem está impregnada de afetividade, já que ocorre a partir das interações sociais, num processo vincular. Pensando, especificamente, na aprendizagem escolar, a trama que se tece entre alunos, professores, conteúdo escolar, livros, escrita, etc. não acontece puramente no campo cognitivo. Existe uma base afetiva permeando essas relações (p. 03-04).

A partir da consideração de que, "a aprendizagem ocorre a partir das interações sociais, em processo vincular”, e considerando a afirmativa de Tassoni, de que, existem experiências subjetivas que revelam como o sujeito é afetado pelos acontecimentos, ou pelo sentido que cada acontecimento apresenta para ele, pode-se inferir que seria importante que a afetividade permeasse todo processo de ensino-aprendizagem, a partir da escolha do professor pela turma que irá atuar. A participante ao ser inquerida sobre o porquê da escolha por uma sala de alfabetização, afirma que:

Foi falta de opção mesmo. Como sou nova no cargo, pela classificação, fiquei com o que sobrou. (a professora sorri). Quem tem mais pontuação escolhe primeiro. Minha afinidade é com faixa etária maior (p. 7, 2017).

É possível inferir que o processo de atribuição de aulas neste município, poderia ser repensado, a partir das considerações afetivas que permeiam todo processo de ensinoaprendizagem e por permeá-lo, seria interessante, que pudesse começar com uma base afetiva, a partir da escolha da turma. 


\section{Afinidade com faixa etária e alfabetização}

A partir da resposta de $\mathrm{I} / 3$ dos participantes, o resultado foi o item "Afinidade com faixa etária e alfabetização". As professoras afirmaram que escolheram lecionar para o primeiro ano ou segundo ano, porque sentiam afinidade com a faixa etária e a partir dessas afirmações, foi possível que, a afetividade por crianças (faixa etária) influencia algumas escolhas, dessa forma é possível inferir que a consideração pelo vínculo é essencial para o participante da pesquisa e para sua prática pedagógica, uma vez que também relaciona a afinidade pela faixa etária ao gosto pela fase de alfabetização.

"Minha preferência pessoal é trabalhar com as crianças menores. Eu me adéquo melhor com crianças dessa faixa etária" (p5, 2017) e "Eu gosto de ver esse processo de chega da escrita”. "Eu tenho paixão pela alfabetização" (pıo, 2017).

Podemos inferir que ao referenciar a afinidade pela faixa etária e o gosto pela alfabetização, os participantes demonstram compartilhar da concepção de Vygotsky e de Ferreiro, pois o "gostar da alfabetização" pode demonstrar o entendimento do que representa essa fase e o reconhecimento da relevância do aspecto afetivo, que nesse caso, inicia-se com a "afinidade pela faixa etária".

\section{Aspecto maternal na alfabetização}

Embora, apenas duas participantes tenhas inferido aspectos maternais em suas respostas, foi elencado por ser considerado um aspecto curioso e esse aspecto pode indicar que os professores participantes relacionam a alfabetização à aspectos afetivos-familiares, principalmente maternal. Dessa forma, surgiu o item Aspecto Maternal na alfabetização.

"Quando meu filho entrou na fase de alfabetização [...]. Então participei fielmente deste processo em casa. $[\ldots .] ".\left(\mathrm{P}_{4}, 2017\right.$.

"Sempre admirei o professor alfabetizador ... Meu filho teve dificuldades e comecei a ajuda-lo. A partir daí me identifiquei”. (Pr3,2017).

A fala das professoras revela a relação afetiva que estabelecem com a alfabetização, seus sentidos pessoais que provavelmente são resultados dessa relação com seus filhos durante o processo de alfabetização. Na perspectiva de Falabelo e Leão, (2005), existe grande relevância da relação sujeito-sujeito para a aprendizagem, "as formas como pensamos, agimos e nos comportamos, sentimos, amamos e odiamos - a nossa vida cognitiva e afetiva - são socialmente constituídas" (p.igr). 
Assim, a relação sujeito-sujeito na aprendizagem, que é uma relação social, resulta em apropriação e construção de conhecimentos, numa ação dialógica, professor-alunoconhecimento, ou no caso das professoras, mãe-filho-conhecimento. Esse processo que se desenvolve permeado pela afetividade, levou as professoras a partir da situação e sentimentos e fazerem escolhas profissionais a partir de concepções construídas com base nesta experiência.

\section{Percepções docentes sobre afetividade}

As professoras entrevistadas ao serem perguntadas sobre o que é afetividade, atribuíram-lhe estreita relação com vínculo. Deixaram claro que, afetividade é o vínculo que estabelecemos nas relações e considerando o contexto educacional das entrevistas, entendem ainda como o vínculo que se estabelece na relação professor-aluno. As respostas:

“É o vínculo que a criança faz, principalmente por meio do respeito" (p2, 2017).

"A criança quando gosta do professor, tende a aprender muito melhor" (p3, 2017).

"É o vínculo que é criado entre professor e aluno. Esse vínculo permite uma interação maior" (p8, 2017).

Nesta perspectiva, Tassoni (2012) apresenta a afetividade como uma qualidade das relações humanas e das experiências, que através das relações sociais, especialmente as que marcam a vida humana, lhes confere um sentido afetivo, afirmativa essa, que tem sua base em Wallon (1968) que define a afetividade como um domínio funcional que se desenvolve a partir de fatores orgânicos e social, sendo inicialmente determinada somente por fatores orgânicos até passar a ser influenciada pelo meio social, ou seja, refere-se às experiências dos indivíduos e as formas de expressão mais complexas e essencialmente humanas. Afetividade nesta perspectiva é ser afetado pelo sentido atribuído aos acontecimentos da vida.

Para Wallon,

O outro tem como termos substitutivos: o espectador, o interlocutor, a testemunha, o companheiro, o parceiro. É inicialmente recurso, meio, motivo e circunstância da vida individual. Depois quando a pessoa chega a liberar-se, permanece em cada um como interlocutor abstrato, como símbolo da dualidade, como parceiro dos discursos internos conflitais (WALLON, 1959, p. o8).

Assim, Wallon apresenta relevância ao vínculo que a criança estabelece através das relações com o outro e com o meio. Podemos inferir que, nesta questão, as professoras se apropriaram do sentido da afetividade proposto por Wallon na perspectiva educacional, a partindo do contexto de suas práticas. 
O vínculo estabelecido com o aluno, resulta em segurança, confiança e autoestima, e segundo Tassoni (2013), vínculo é resultado de um refinamento nas trocas afetivas entre professor-aluno. Assim, pode-se inferir que as condições de se cultivar o sentimento de segurança, como outros da mesma natureza, podem representar que as professoras buscam cultivar relacionamentos profundos que promovam a aprendizagem significativa. Nesta perspectiva, corroboram com os apontamentos de Tassoni, os autores Santos, Junqueira e Silva (2016) quando afirmam que a segurança surge para a criança a partir do estabelecimento de laços afetivos:

Quando um professor estabelece laços afetivos com seus alunos, ele está criando um ambiente de segurança. Isto pode evitar bloqueios afetivos e cognitivos[...] (2016, p.88).

Isso nos leva a identificar na fala das professoras, que o vínculo, representa para elas, um importante aspecto da afetividade. A percepção de afetividade nesta perspectiva está totalmente ancorada no vínculo nas relações, não só com o professor, mas com seus pares e com o conhecimento.

\section{Afetividade e cognição: as relações que se estabelecem}

Talvez a questão mais relevante na entrevista tenha sido "Você estabelece relação entre afetividade e cognição?" A partir dela, o item "Afetividade e cognição: as relações que se estabelecem" surgiu, demonstrando as impressões dessas professoras sobre a relação entre afetividade e cognição.

Sim. Não tem como a criança se desenvolver no cognitivo se a afetividade não estiver ali. Não tem como a criança se desenvolver no cognitivo se a afetividade não estiver ali. Não tem como a criança aprender o conteúdo, a atividade se ela não tiver um vínculo com a pessoa que está falando. Então eu acredito que...caminham juntos, afetividade e cognitivo. Eles vão estar sempre ali, entrelaçados (p4, 2017).

"Eu estabeleço sim com certeza. Porque a afetividade é o caminho para que a aprendizagem aconteça" (p5, 2017).

Para as professoras, a aprendizagem ocorre a partir do vínculo que o professor estabelece com seu aluno durante o processo de aprendizagem e podemos inferir que a preocupação, paciência, carinho, sentir-se querida, são indicadores se integram ao vínculo entre professor e aluno. Nesta perspectiva destacamos Vygotsky (2003) que enfatiza que a compreensão da leitura e escrita é construída nas relações sociais, com o outro e com o 
conhecimento e pela troca de experiências, isso ocorre em processo trilateral: o aluno, o professor e o meio existente entre eles.

\section{Motivação para aprender}

O item "motivação para aprender" aparece em algumas como aspecto afetivo que se relaciona com a cognição.

"Pensando no aspecto motivacional, a afetividade tem total relação com a cognição, já que o lado emocional e afetivo da criança contribui para a motivação e interesse (pı2, 2017).

"Sim. Acredito que a afetividade tem um papel motivador para a aprendizagem e pode sim auxiliar na aprendizagem, quando essa afetividade é positiva, assim como pode vir a criar bloqueios quando a afetividade é negativa" (pı3, 2017).

Nesta perspectiva, encontramos nos três autores, Wallon, Vygotsky e Piaget, afirmações apresentam a motivação como um importante aspecto para a aprendizagem. Para Wallon (1995), os fenômenos afetivos que ocorrem no ambiente escolar, se relacionam às necessidades e motivos de alunos e professores, e dessa forma, a educação tem a função de atender às necessidades, interesses e aptidões dos alunos. Assim, o professor ao identificar as necessidades dos alunos, pode planejar situações que motive seus alunos e promovam seu sucesso. Vygotsky atribui à motivação, papel essencial para a aprendizagem. Um indivíduo motivado, se emprenha no processo de aprendizagem e por consequência, aprende melhor. $O$ próprio pensamento, segundo o autor é fruto da motivação:

O pensamento propriamente dito é gerado pela motivação, isto é, por nossos desejos e necessidade, nossos interesses e emoções. Por trás de cada pensamento há uma tendência afetivo-volitiva, que traz em si a resposta ao último "por que" de nossa análise do pensamento. Uma compreensão plena e verdadeira do pensamento de outrem só é possível quando entendemos sua base afetivo-volitiva (VYGOTSKY,1987, p. I29).

Assim afetividade e cognição relacionam-se a partir da base afetiva-volitiva e dessa forma, no contexto escolar Vygotsky (2007) considera a escola como espaço em que se deve concentrar esforços na motivação dos alunos para ativar seus recursos cognitivos e nesse enfoque é importante que seja considerada essencial. Foi possível observar nos relatos que as professoras compreendem a motivação como um aspecto da afetividade e atribuem grande importância para o desenvolvimento cognitivo e aprendizagem de seus alunos.

Piaget (199I) relaciona afetividade à cognição, uma vez que, afirma que as experiências afetivas estão presentes em todas as fases do desenvolvimento da criança. Assim, paralelo ao 
desenvolvimento cognitivo encontra-se o afetivo, e o afeto nesta perspectiva, inclui sentimentos, interesses, desejos, etc. Para o autor,

É impossível encontrar um componente oriundo apenas da afetividade, sem nenhum elemento cognitivo. É, igualmente, impossível encontrar um comportamento composto só de elementos cognitivos [...] embora os fatores afetivos e cognitivos sejam indissociáveis num dado comportamento, eles parecem ser diferentes quanto à natureza [...] é óbvio que os fatores afetivos estão envolvidos, mesmo nas formas mais abstratas de inteligência. Para um estudante resolver um problema de álgebra ou para um matemático descobrir um teorema, deve haver um interesse intrínseco, um interesse extrínseco ou uma necessidade de partida. Enquanto trabalha, estados de prazer, desapontamento, ansiedade tanto quanto sentimentos de fadiga, esforço, aborrecimento, etc., entram em cena. Ao finalizar o trabalho, sentimentos de sucesso, ou fracasso podem ocorrer; e, finalmente o estudante pode experimentar sentimentos estéticos fluindo da coerência de sua solução (PIAGET,198Ib, p.2-3).

A motivação neste enfoque, seria um dos acionadores que leva o indivíduo a aprender, pois é o interesse que influencia a seleção das atividades intelectuais, ou seja, nos esforçamos para aprender aquilo que nos interessa, o que nos motiva. Pode-se inferir a partir das falas das professoras que, um dos principais aspectos para a aprendizagem é a motivação e que, quando o professor motiva seu aluno, estabelece relação entre afetividade é cognição. A motivação nesta perspectiva seria uma dimensão da afetividade, dessa forma, é a motivação que leva o aluno a sentir necessidade em aprender e atribuir sentido ao que aprende.

\title{
Indisciplina em classe
}

A categoria "indisciplina em classe" surge a partir da análise dos discursos, em que alguns dos professores colocam a afetividade como instrumento para manter certa "ordem em sala de aula.

\begin{abstract}
Sim. Um exemplo de um aluno indisciplinado da minha sala. Que os próprios pais chegaram e falaram: Não, ele é assim mesmo, ano passado reclamavam das mesmas situações. ", Mas eu descobri que se eu puxasse ele pro meu lado, dando atenção, mostrando... não somente neh, chamando atenção o tempo inteiro, mas neh, tá trazendo ele pro meu lado tratando ele de uma forma diferente, dando elogios para ele. Assim, eu tenho ganhado ele. Eu tô conseguindo. Eu acredito que há várias formas de ser afetivo. Acredito que empatia também seria uma forma de ser afetivo (p4, 2017).
\end{abstract}

Algumas falas, por exemplo, a citada acima, consideram a afetividade como um meio de aproximar-se do aluno e que isso, consequentemente resulta em uma sala disciplinada. 
Alguns relatos chegam a demonstrar relação entre afetividade e forma de controle, como no caso da professora.

\section{Considerações finais}

Esta pesquisa é resultado da compreensão de como professores alfabetizadores percebem a afetividade na sua prática, assim como a importância e a relação que estabelecem entre afetividade e aprendizagem. Primeiramente, houve a dificuldade que a pesquisadora enfrentou dentro do campo de pesquisa na sua investigação, pois, nos primeiros momentos, durante a apresentação nas unidades escolares, os olhares dos professores demonstravam desconfiança em relação à proposta.

Houve a necessidade de uma explicação sobre a pesquisa, a necessidade dos dados e os frutos que poderiam brotar desse material. Assim, a desconfiança inicial começou a dar lugar à curiosidade sobre a temática da pesquisa, o que gerou até a possibilidade de palestras nas escolas sobre o tema afetividade. A cada questão da entrevista, as participantes revelavam suas opiniões e fazíamos uma discussão, pesquisadora e participante, sobre o tema de cada pergunta.

Uma situação interessante percebida foi o descontentamento com relação à escolha das classes. A maioria das participantes não se conformava com a política de atribuição de aulas por classificação. Alegavam que, pelo menos para a alfabetização, o critério poderia ser diferente, uma vez que, para alfabetizar, segundo elas, há a necessidade de muito mais paciência, carinho, dedicação, além de conhecimentos sobre a prática de alfabetização. Apontaram a importância das características citadas, também por considerarem que I. e 2.. anos, são fases em que a criança está em processo de aquisição da escrita e, em simultâneo, passando por uma mudança que é a saída do ensino infantil para o ensino fundamental, de uma etapa em que o brincar imperava, as mesas eram coletivas, as professoras eram "tias" e a cobrança pela leitura e escrita era menor, para a etapa em que as brincadeiras estão mais presentes nas aulas de Educação Física, em que é preciso aprender a ler e há a cobrança de ficar horas sentados.

$\mathrm{Na}$ relação entre afetividade e cognição, o vínculo com o professor é considerado como fator principal, que impulsiona o processo de alfabetização e, junto à motivação para aprender, outro fator destacado, constitui uma das dimensões da afetividade na aprendizagem.

Sobre as contribuições que a afetividade pode trazer para a aprendizagem, o fator da motivação apareceu na maioria dos relatos de suas experiências. Assim, foi possível inferir que o aspecto afetivo mais presente na prática alfabetizadora é a motivação. Um aspecto curioso 
relatado por grande parte dos participantes é o de que por meio da afetividade é possível obter alunos disciplinados. Para as participantes, lançar mão de aspectos afetivos, como vínculo e motivação, pode contribuir significativamente para "manter a ordem" em sala de aula para que a alfabetização aconteça.

Diante desses apontamentos, talvez fosse interessante, em estudos futuros, outra investigação, para detectar a concepção de indisciplina dos professores, pois conceitos como "interação", "diálogo" e "troca de ideias" agitam a sala, mas são essenciais para a aquisição da leitura e escrita e não devem ser confundidos como indisciplina.

O estudo demonstrou, por meio das situações relatadas, que as professoras, por meio do respeito, compreensão, diálogo, carinho, motivação, têm conseguido êxito na alfabetização. Dessa forma, é essencial lembrar a importância de o professor valorizar o aluno e motivá-lo, pois, são essas atitudes que promovem o aumento da autoestima e, por consequência, um melhor desempenho na aprendizagem, quer seja na alfabetização ou em estágios mais adiantados. No entanto, não se deve esquecer dos aspectos cognitivos e a necessidade de estimular seu desenvolvimento, a aprendizagem, pois, o desenvolvimento da cognição é essencial ao processo de ensino-aprendizagem.

Um aspecto curioso relatado por grande parte dos participantes é o de que por meio da afetividade é possível obter alunos disciplinados. Para as participantes, lançar mão de aspectos afetivos, como vínculo e motivação, pode contribuir de forma significativa para "manter a ordem" em sala de aula para que a alfabetização aconteça.

Diante desses apontamentos, talvez fosse interessante, em estudos futuros, outra investigação, para detectar a concepção de indisciplina dos professores, pois conceitos como "interação", "diálogo" e "troca de ideias" agitam a sala, mas são essenciais para a aquisição da leitura e escrita e não devem ser confundidos como indisciplina.

\section{Referências}

ALEXANDROF, Marlene Coelho. O Papel das emoções na constituição do sujeito. Constr. Psicopedagógicas. [online]. 2012, vol.20, n.20, pp. 35-56. ISSN I4156954

AZEVEDO, C. A mediação das emoções em professores alfabetizadores. I. ${ }^{\text {a }}$ edição Curitiba: Appris, 2015. 
A Práxis do Professor Alfabetizador e a Aprendizagem. I. a edição. São Paulo: Expressão e Arte Editora, 2012

AZEVEDO, F. de. A transmissão da cultura. Parte 3 da 5 ed. da obra. São Paulo: Melhoramentos, 1976.

BARDIN. L. (2010). Análise de conteúdo. Trad. Luís Antero Reto e Augusto Pinheiro Lisboa: Edições 70

FALABELO, R. N. O.; LEÃO, D.S. A mediação da afetividade em experiências teórico-metodológicas de leitura e escrita. Revista Margens Interdisciplinar, v. 7, n. 8, p. I89-213, maio 2016. ISSN 1982-5374. Disponível em: 〈https://periodicos.ufpa.br/index.php/revistamargens/article/view/2755>. Acesso em: 04 jun. 2017.

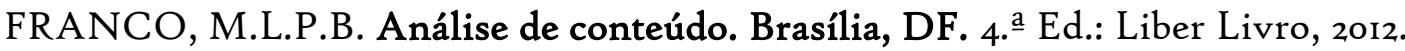

FERREIRO; E. TEBEROSKY, A. Psicogênese da língua escrita. Porto Alegre: Artmed, 1986

FERREIRO; E. Reflexões sobre alfabetização. São Paulo, Editora Cortez, 1987

GLEIZER, M. A. Espinosa \& a afetividade humana. Rio de Janeiro: Jorge Zahar, 2005 LAKATOS, E.M; MARCONI. M. de A. Fundamentos de Metodologia Científica. 5. ed. São Paulo: Atlas, 2003

LA TAILLE, Y. OLIVEIRA; M. DANTAS, H. Teorias Psicogenéticas em discussão. São Paulo: Summus, 1992

LEITE, S. A. S.; TASSONI, E. C. M. A afetividade em sala de aula: as condições do ensino e a mediação do professor. In: AZZI, R. G.; SADALLA, A. M. F. A. Psicologia e formação docente: desafios e conversas. São Paulo: Casa do Psicólogo, 2002

LEITE, S.A.S. Afetividade nas práticas pedagógicas. Temas psicol. [online]. 2012, vol.20, n.2, pp. 355-368. ISSN 1413-389X. Disponível em http://dx.doi.org/ro.9788/TP2012.2-o6 (acesso em 20/o6/2017)

LEITE, S.A.S.; TASSONI, E.C.M. Afetividade no processo de ensino-aprendizagem: as contribuições da teoria walloniana. Educação (Porto Alegre, impresso),v. 36, n. 2, p. 262-271, maio/ago.2013.

Disponível: http://revistaseletronicas.pucrs.br/ojs/index.php/faced/article/download/9584/9457 (acesso em Io/ro/2017)

MACIEL, F. I. P. História da Alfabetização: perspectivas de análise. In: VEIGA, C. G; FONSECA, T. N. L (Orgs). História e Historiografia da educação no Brasil. Belo Horizonte: Autêntica, 2008 
MEllo, T.; RUBIO, J. A Importância da Afetividade na Relação Professor/Aluno no Processo de Ensino/Aprendizagem na Educação. Revista Eletrônica Saberes da Educação - Volume 4 - no $\mathrm{I}-$ 2013. Disponível em http://docs.uninove.br/arte/fac/publicacoes/pdf/v4-nI-2013/Tagides.pdf (acesso em I2/04/2017)

MENDES, T.C; LAROCCA, P. Formação docente e afetividade: concepções sobre o papel da afetividade no desenvolvimento infantil. Publ. UEPG Ci. Hum., Ling., Letras e Artes, Ponta Grossa, 21 (2): 157-168, jul./dez. 2013. Disponível em http://www.revistas2.uepg.br/index.php/humanas

MORTATTI, M. R. L. História dos métodos de alfabetização no Brasil, 2006. Disponível em: http://portal.mec.gov.br/seb/arquivos/pdf/Ensfund/alf_mortattihisttextalfbbr.pdf. Acesso em abril/2015

. Os sentidos da alfabetização. São Paulo: Editora UNSP: CPNED, 2000

OLIVEIRA, M. K. de, \& Rego, T. C. (2003). Vygotsky e as complexas relações entre cognição e afeto. In Afectividade na escola: alternativas teóricas e práticas. São Paulo: Summus.

PAIVA, J. M. de. Educação jesuítica no Brasil colonial. In: LOPES, E. M. T.; FARIA Filho, L. M; VEIGA, C. G. (Orgs). 500 anos de educação no Brasil. Belo Horizonte: Autêntica, 2000.

PIAGET, J. A construção do real na criança. São Paulo: Ática, 200 I. O desenvolvimento do pensamento: equilibração das estruturas cognitivas.

Lisboa: Dom Quixote, 1981.

PIMENTEL, M.A.M. Reflexões Construtivistas. Belo Horizonte, In: Caderno Amae, n. $\stackrel{\circ}{2}, 1992$

SANTOS, A.O.; JUNQUEIRA, A.M.R.; SILVA, G.N. A afetividade no processo de ensino-aprendizagem: diálogos em Wallon e Vygotsky. Perspectivas em Psicologia, Uberlândia, vol. 20, n. I, pp. 86 - IoI, Jan/Jun, 2016. Disponível em http://www.seer.ufu.br/index.php/perspectivasempsicologia/article/view/35591 (acesso em i7/05/2017)

SILVA, M. L. S.; CRUZ, V. A.; SILVA, F.F. A Dimensão Afetiva e Sua Relevância No Processo De Ensino-Aprendizagem. REGET, V. I8, N. 4, DEZ., 2014. Disponível em https://periodicos.ufsm.br/reget/article/view/14045 (acesso em ro/o6/2017) 
TASSONI, E. C. M. Afetividade e aprendizagem: A relação professor e aluno. Educação (Porto Alegre, impresso), v. 36, n. 2, p. 262-271, maio/ago. 2013. disponível em http://23reuniao.anped.org.br/textos/2019t.pdf (acesso em Io/o5/2018).

TASSONI, E.C. M. A afetividade e o processo de apropriação da linguagem escrita. In LEITE, S. A. S (org.). Alfabetização e Letramento: contribuições para as práticas pedagógicas. Campinas, SP: Komedi: Arte Escrita, 2001.

TASSONI, E.C.M. Afetividade na aprendizagem da leitura e da escrita: uma análise a partir da realidade escolar. Revista Estudos e Pesquisa em Psicologia. Rio de Janeiro v. 13 n. 2

Disponível em http://www.epublicacoes.uerj.br/index.php/revispsi/article/view/8423/6256 (acesso em 13/o4/2017)

VYGOTSKY, L.S. Pensamento e linguagem. São Paulo: Martins Fontes, 1993. . O desenvolvimento psicológico na infância. São Paulo: Martins Fontes, 1998 A construção do pensamento e da linguagem. São Paulo: Martins Fontes, 2000.

.A formação social da mente: o desenvolvimento dos processos psicológicos superiores. São Paulo: Martins Fontes, 2007

WADSWORTH. B. J. Inteligência e Afetividade da Criança na Teoria de Piaget. São

Paulo: Pioneira, 1995

WALlON, H. (1941-1995). A evolução Psicológica da criança. Lisboa, Edições 70 (1959-1975). Psicologia e Educação na infância. Lisboa, Estampa

Do acto ao pensamento. Lisboa: Moraes Editores, 1968

http://portal.mec.gov.br/plano-nacional-de-formacao-de-professores/censo-do-professor (acesso em 15/05/2018)

http://portal.inep.gov.br/indicadores-educacionais (acesso em I5/05/2018) https://www.ibge.gov.br/estatisticas-novoportal/sociais/educacao.html (acesso em I505/2018) 